\title{
A case-control study of cervical cancer screening in north east Scotland
}

\author{
J ELIZABETH MACGREGOR, SUSAN M MOSS, D MAXWELL PARKIN, NICHOLAS E DAY
}

\begin{abstract}
To estimate the relative risk of invasive cervical cancer in each succeeding year after a negative screening result the screening records of all women tested in the north east of Scotland were examined as the basis for a case-control study. The cases consisted of 115 women in whom invasive cervical cancer had been diagnosed in 1968-82 and who had appeared in the screening records at least once before diagnosis. For each patient five controls were selected from women of the same age who appeared in the screening records before the date of diagnosis in the patient. If the patient's cancer had been detected by screening the controls were chosen from women of the same age screened the same year. A comparison was made between cases and controls of the number of negative smears taken before the diagnosis.

The results showed a high relative protection (inverse of the relative risk) in the first two years after a negative test, falling steadily as time since the last negative test elapsed. Even after 10 years, however, a considerable residual effect was observed.
\end{abstract}

\section{Introduction}

Considerable evidence exists for the effectiveness of cervical cytology screening in preventing invasive carcinoma of the cervix. This derives from comparisons of time trends and geographical differences in incidence in relation to screening activity and from uncontrolled studies comparing incidence in screened and unscreened groups of women. ${ }^{12}$ A recent approach to the evaluation of non-experimental screening programmes is the use of case-control studies. $^{3}{ }^{4}$ Sasco et al (unpublished data) have considered the design of such studies in detail, in particular the different approaches required according to whether the screening test studied is intended to detect early invasive disease or a precancer state.

Although screening for cervical cancer is generally accepted to be effective in reducing morbidity and mortality from the disease, less agreement exists on how often and to whom screening should be offered. Here we consider the question of how often screening should be offered. One way in which this question may be considered is in terms of the reduction in risk of invasive disease among women with a previous negative smear in terms of the time elapsed since the smear was taken. The risk will be relatively low immediately after a negative result and will rise as time elapses if further screening is not

Department of Pathology, University of Aberdeen, Aberdeen

J ELIZABETH MACGREGOR, MD, FRCPATH, senior lecturer and consultant

Unit of Descriptive Epidemiology, International Agency for Research on Cancer, 69372 Lyon Cedex 08, France

SUSAN M MOSS, MSC, research fellow

D MAXWELL PARKIN, MD, medical officer

Unit of Biostatistics and Field Studies, Division of Epidemiology and Biostatistics, International Agency for Research on Cancer

NICHOLAS E DAY, PHD, chief

Correspondence to: Dr N E Day. performed. Once the risk has become unacceptably high-for example, $20 \%$ of that among unscreened women-a further screening test would be indicated. The increase in risk after a negative smear depends on the duration of the preclinical detectable phase and on the sensitivity of the test. ${ }^{5}$ One way of estimating the distribution of the preclinical phase is by comparing age specific incidences of varying degrees of dysplasia in situ and microirvasive lesions with corresponding incidences

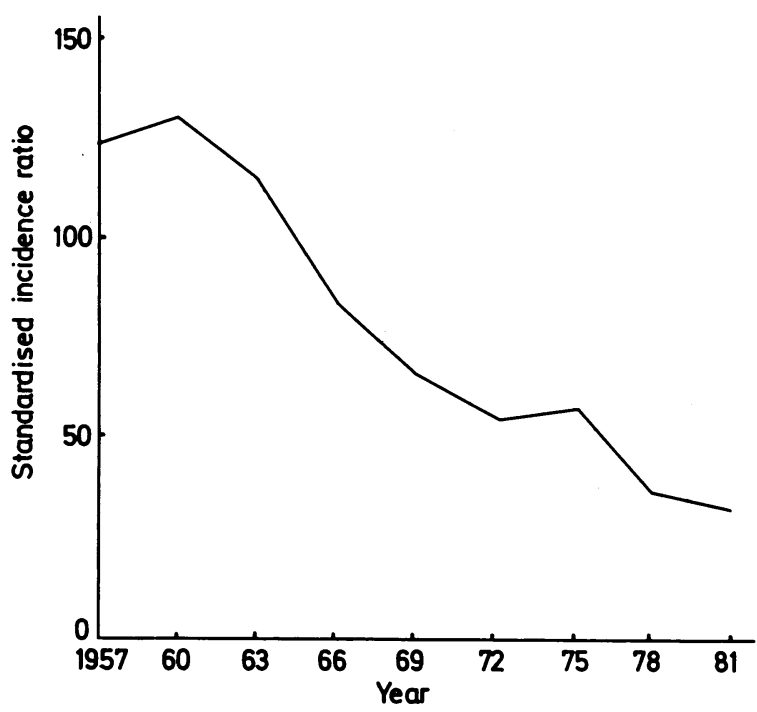

Change in standardised incidence ratio for cervical cancer in Aberdeen, 1957-81. (Incidences indirectly standardised to the incidence for the rest of Scotland, 1960.)

for invasive cancer. ${ }^{6} \mathrm{~A}$ major drawback of this approach, apart from the subjective nature of the diagnosis of cervical intraepithelial neoplasia, is its insensitivity to the left hand tail of the distribution-that is, the proportion of lesions that progress relatively rapidly. This proportion, however, is precisely the quantity of interest as the more slowly developing lesions would be detected by almost any screening strategy. ${ }^{7} \mathrm{~A}$ more sensitive approach to estimate the left hand tail of the distribution is to follow up a population of women after they have yielded a negative screening result and to observe directly the increasing incidence of invasive disease. ${ }^{8}$ Rather than calculate incidences from the entire cohort relative changes in incidence may be obtained by sampling from the cohort-a case-control approach.

Here we report the results of such a case-control study, using the screening records of women examined as part of the programme in the Grampian (north east) region of Scotland. This programme was started in $1960^{\circ}$ and aimed at the initial examination of all married women aged 25-60, followed by rescreening every five years. ${ }^{10}$ The figure shows the reduction in the incidence of cervical cancer in the city of Aberdeen since the start of the programme. The central pathology laboratory in Aberdeen analyses all of the smears performed in the region, and the records of individuals are matched and collated, so that a complete screening history is available for all women who have had at least one smear. The cases in our study comprised all patients with invasive cervical cancer, and 
TABLE I-Relative protection according to time since last negative smear

\begin{tabular}{|c|c|c|c|c|c|c|c|c|c|}
\hline & \multicolumn{7}{|c|}{ Months since last negative smear } & \multirow{2}{*}{$\begin{array}{c}\text { No previous } \\
\text { negative } \\
\text { smear }\end{array}$} & \multirow{2}{*}{ Total } \\
\hline & $0-11$ & $12-23$ & $24-35$ & $36-47$ & $48-71$ & $72-119$ & $\geqslant 120$ & & \\
\hline $\begin{array}{l}\text { Patients with symptomatic cervical cancer } \\
\text { Controls } \\
\text { Patients with screening detected stage I cervical cancer } \\
\text { Controls }\end{array}$ & $\begin{array}{r}0 \\
20 \\
0 \\
10\end{array}$ & $\begin{array}{r}1 \\
14 \\
1 \\
35\end{array}$ & $\begin{array}{r}4 \\
23 \\
1 \\
28 \\
\end{array}$ & $\begin{array}{r}5 \\
20 \\
3 \\
24 \\
\end{array}$ & $\begin{array}{r}7 \\
24 \\
11 \\
90\end{array}$ & $\begin{array}{r}6 \\
12 \\
4 \\
14\end{array}$ & $\begin{array}{r}12 \\
26 \\
4 \\
8 \\
\end{array}$ & $\begin{array}{l}26 \\
41 \\
\end{array}$ & $\begin{array}{r}35 \\
139 \\
50 \\
250\end{array}$ \\
\hline $\begin{array}{l}\text { Relative protection } \\
95 \% \text { Confidence interval }\end{array}$ & & $\begin{array}{l}8 \cdot 9 \\
1 \cdot 8-44 \cdot 4\end{array}$ & $\begin{array}{l}3 \cdot 5 \\
1 \cdot 1-11 \cdot 2\end{array}$ & $\begin{array}{l}2 \cdot 3 \\
0.8-6.5\end{array}$ & $\begin{array}{l}1 \cdot 9 \\
0 \cdot 4-4 \cdot 5\end{array}$ & $\begin{array}{l}1 \cdot 0 \\
0.4-3.9\end{array}$ & $1 \cdot 0$ & $\begin{array}{l}0 \cdot 3 \\
0 \cdot 1-0.9\end{array}$ & \\
\hline
\end{tabular}

the exposure of interest was the screening history in terms of the number and timing of negative smears.

This study is part of a larger programme coordinated by the International Agency for Research on Cancer in which the results of several screening programmes are being evaluated in a similar way.

\section{Subjects and methods}

All cases of invasive squamous carcinoma of the cervix for the years 1968 to 1982 in the Grampian region were identified from the inpatient records and records of the central pathology laboratory or the regional cancer registry, or both. The screening histories of the patients with cervical cancer were determined; the case series for the present study comprised those 115 women with cervical cancer who had attended for screening at least once. Only $16(14 \%)$ of the women concerned were aged under 35, and $22(19 \%)$ were aged 60 or over.

Controls were drawn from a computer file comprising the screening histories of a $10 \%$ random sample of all women in the region who had undergone at least one screening test.

The women with cervical cancer were separated into two groups: those whose cancer was judged to have presented symptomatically (group $1 ; n=35$ ) and those whose cancer had been detected by routine screening (group $2 ; n=80$ ). Of those in group 2,50 had stage I tumours at diagnosis and were considered to be asymptomatic, screen detected cases. Thirty, however, had tumours of stage II or worse and may well not have admitted to symptoms at the time of diagnosis.

It was evident that the screening histories of the patients in groups 1 and 2 differed as many of the women in group 2 had attended about five years after their previous screening test, in response to an invitation to rescreening. Controls for the two groups were therefore drawn separately. Five random controls, matched for year of birth and with the additional constraint that each must have entered the study (at the time of her first negative smear) before the date of diagnosis of cancer in the patient, were drawn for each of the 35 women in group 1. Five controls were again drawn, according to the same criteria, for each of the 80 women with cancer detected by screening, but from women who had been screened within six months either side of the date of the screening test at which the cancer was diagnosed. This was to ensure that both patients and controls were drawn from the same population of women-namely, those attending for routine (asymptomatic) screening.

The screening histories of patients and controls were summarised in an identical manner. The definition of a negative Pap test was based on the definition of positive smears used by Boyes et al..$^{11}$ Their "class 3" or worse smears we classified as positive. "Class 2" corresponded to a smear reported to be atypical in our study; such smears were classified as positive if three or more consecutive smears in the same woman were class 2 , if there were two or more consecutive class 2 smears spanning an interval of 10 months or more, or if the smear was followed directly by a smear of class 3 or higher or by a histological demonstration of dysplasia or carcinoma in situ or invasive carcinoma.

Any smears that had been recorded as "unsatisfactory" were excluded, and any negative smear occurring within six months of a previous negative smear was discounted, as an attempt to eliminate bias due to smears being repeated once or more before a diagnosis was made.

For each subject the number of negative smears and the length of time between the last negative smear and date of exit were computed. The date of exit for patients was taken as the date of diagnosis; for controls it was the date of diagnosis of the matched patient. The screening test at time of diagnosis was not included in the screening history of either patients in group 2 or their controls. Counting of negative smears was stopped at the first occurrence of a positive smear because of the likelihood of subsequent negative smears being false negatives.

As no records of emigration were available from the population we did not know whether all the controls for the women in group 1 were still alive and resident in the region at their date of exit. Of these 175 controls, 77 had further screening records after this date; details of the remaining 98 were sent to the National Health Service central register, and 62 of these were confirmed as being present in Aberdeen at the time of diagnosis of their matched patient. We did not include the remaining 36 controls who were not traced in the register as we could not be certain that they were resident at the date on which their matched patient was diagnosed, although their inclusion made little difference to the results. The controls of the patients in group 2 were by definition still present at the date of exit as they were screened at this time.

The analysis was first carried out separately for groups 1 and 2, group 2 being restricted to the 50 patients with tumours detected at stages IA to IB as a further attempt to exclude any cases that were in reality symptomatic and had been diagnosed by a non-routine smear. The two groups were then combined and a test for heterogeneity carried out.

A logistic regression analysis with conditional likelihood functions was used to estimate the relative risks associated with time since last negative smear for different time intervals compared with 10 or more years and for different numbers of previous negative smears compared with one previous negative. The analysis was done with the computer program PECAN. ${ }^{22}$ The results obtained were similar to those from a classic analysis for the variables considered separately, but the logistic approach allowed the joint effect to be modelled and provided a way of handling the variable number of controls per case resulting from the exclusion of some of the controls for the patients in group 1.

\section{Results}

The effect of screening is expressed here as "relative protections" - that is, the inverses of the relative risks. The reference category for these estimates of relative protection is the group of women with a negative screening result obtained 10 or more years previously.

Of the women with cancer detected by screening (group 2) at stage IA or IB, $26(52 \%)$ had cancer diagnosed at their first appearance and had no record of a previous smear in the Grampian screening programme. Only $41(16 \%)$ of their controls had not undergone a previous test, so that the relative protection of at least one previous negative smear was 5.5 (unmatched analysis, $95 \%$ confidence interval $3 \cdot 0-10 \cdot 1)$. Of the women with symptomatic cancer (group 1), $23(66 \%)$ had had a negative smear less than 10 years before diagnosis compared with $113(81 \%)$ of the controls, giving a relative protection of 2.3 for a negative screen within the past 10 years (unmatched analysis, 95\% confidence interval $1 \cdot 0-5 \cdot 3$ ).

Table I shows the effect of length of time from last negative smear to diagnosis. As a test for heterogeneity showed no significant difference between the estimates for symptomatic and screen detected cases the pooled estimates of relative protection are presented. In neither group did any cases have a negative smear in the 12 months before diagnosis, giving an "infinite" relative protection in this category. Thereafter the relative protection decreased progressively with increasing time since last negative smear, with a relative protection of $1.9(95 \%$ confidence interval $0.4-4.5)$ remaining at 48 71 months; the trend among those with at least one previous negative smear was highly significant $\left(\chi^{2}=28.6, p<0.0001\right)$. There was an apparent threefold relative risk of no previous negative smear against one 10 or more years before diagnosis. 
Table II shows the equivalent results for patients in group 2 with tumours of stage II or worse. None of these patients had had a negative smear within 36 months before diagnosis, and the apparent relative risk of no previous negative smear against one 10 or more years before diagnosis was 10 -fold. There were 22 patients $(73 \%)$ with no smear before the one leading to the diagnosis of invasive cancer; many of them may have presented with symptoms, and there may be a high proportion of women who never attend screening programmes and are at intrinsic high risk, so that this value of 10 -fold may be biased upwards.

Table III shows the effect of number of previous negative smears. Again, the relative protections are a pooled estimate for the two groups of cases. An apparent protective effect was found for three or more previous negative smears compared with only one previous negative (relative protection $=5 \cdot 2,95 \%$ confidence interval $1 \cdot 9-15 \cdot 2$ ). Tables IV and $\mathrm{V}$ give the relative protection associated with the number of previous tests and the interval since the last negative smear, while simultaneously controlling for the other variable. The protection achieved by increasing the number of previous tests from one to three or more was considerably reduced $(2.7$ in place of 5.2$)$ and no longer significant $(95 \%$ confidence interval $0.9-8 \cdot 6)$, whereas the effect of time since last negative smear did not alter substantially.
TABLE $\mathrm{V}-$ Relative protection with time and number of negative smears

\begin{tabular}{lccc}
\hline & \multicolumn{3}{c}{$\begin{array}{c}\text { No of negative smears } \\
\text { (after adjustment for time since last negative smear) }\end{array}$} \\
\cline { 2 - 4 } & 1 & 2 & $\geqslant 3$ \\
\hline $\begin{array}{l}\text { Relative protection } \\
95 \% \text { Confidence interval }\end{array}$ & 1.0 & 0.8 & $2 \cdot 7$ \\
\hline
\end{tabular}

who have attended for routine screening and adjusting for the number of previous negative tests.

The screening histories of patients and controls were derived from records of attendance in the Grampian region, and the possible effects of migration leading to incomplete ascertainment of screening history must be considered. The potential bias due to incomplete screening histories in controls who might have left the region before the date of diagnosis of the matched patient was avoided by the exclusion of all such women from the analysis. In addition, for the patients with asymptomatic

TABLE II-Relative protection according to time since last negative smear for women with cervical cancer of stage II or worse detected by screening

\begin{tabular}{|c|c|c|c|c|c|c|c|}
\hline & \multicolumn{5}{|c|}{ Months since last negative smear } & No previous negative smear & Total \\
\hline $\begin{array}{l}\text { Patients with screening detected stage II cancer } \\
\text { Controls }\end{array}$ & $\begin{array}{r}0 \\
35\end{array}$ & $\begin{array}{r}2 \\
26\end{array}$ & $\begin{array}{r}3 \\
49\end{array}$ & $\frac{1}{5}$ & $\begin{array}{l}2 \\
9\end{array}$ & 22 & $\begin{array}{r}30 \\
150\end{array}$ \\
\hline Relative protection & & $6 \cdot 6$ & 10.5 & $2 \cdot 1$ & $1 \cdot 0$ & $0 \cdot 1$ & \\
\hline
\end{tabular}

TABLE III-Relative protection according to number of negative smears

\begin{tabular}{|c|c|c|c|c|c|}
\hline & \multicolumn{4}{|c|}{ Number of negative smears } & \multirow{2}{*}{ Total } \\
\hline & None & 1 & 2 & $\geqslant 3$ & \\
\hline $\begin{array}{l}\text { Patients with symptomatic cervical } \\
\text { cancer } \\
\text { Controls } \\
\text { Patients with screen detected stage I } \\
\text { cervical cancer } \\
\text { Controls }\end{array}$ & $\begin{array}{l}26 \\
41\end{array}$ & $\begin{array}{l}22 \\
69 \\
15 \\
78\end{array}$ & $\begin{array}{r}10 \\
35 \\
7 \\
7 \\
60\end{array}$ & $\begin{array}{r}35 \\
35 \\
71\end{array}$ & $\begin{array}{r}35 \\
139 \\
\\
50 \\
250\end{array}$ \\
\hline $\begin{array}{l}\text { Relative protection } \\
95 \% \text { Confidence interval }\end{array}$ & $\begin{array}{l}0 \cdot 2 \\
0 \cdot 1-0.5\end{array}$ & $1 \cdot 0$ & $\begin{array}{l}1 \cdot 2 \\
0 \cdot 6-2 \cdot 4\end{array}$ & $\begin{array}{l}5 \cdot 2 \\
1 \cdot 9-15 \cdot 2\end{array}$ & \\
\hline
\end{tabular}

TABLE IV-Relative protection with time since last negative smear

\begin{tabular}{llllllll}
\hline & \multicolumn{5}{c}{$\begin{array}{c}\text { Months since last negative smear } \\
\text { (after adjustment for number of smears) }\end{array}$} \\
\cline { 2 - 7 } & $0-11$ & $12-23$ & $24-35$ & $36-47$ & $48-71$ & $72-119$ & $\geqslant 120$ \\
\hline Relative protection & 6.9 & 3.4 & $1 \cdot 7$ & 1.6 & 1.0 & 1.0 \\
$95 \%$ Confidence interval & $1.3-37-7$ & $1.0-11.4$ & $0.5-5 \cdot 2$ & $0.7-3.9$ & $0.4-2 \cdot 7$ & \\
\hline
\end{tabular}

\section{Discussion}

One of the problems associated with case-control studies of screening is that of selection bias. Known risk factors for cervical cancer have been shown to be inversely related to probability of attending for screening ${ }^{13}$; this would lead to overestimation of the relative protection associated with a previous smear and may have accounted for some of the large protective effect $(5 \cdot 5)$ of one or more tests versus none in the patients with cervical cancer detected by screening. A relative protection of this magnitude, however, cannot plausibly be ascribed to confounding, ${ }^{14}$ so presumably much of the effect was real. The main interest, moreover, lies in the relative protections associated with different times since the last negative test. These estimates are modified only slightly by adjusting for the number of previous negative tests (comparison of tables I and IV). We consider it unlikely that any substantial degree of confounding would remain after both limiting the study to those women cervical cancer (those in group 2) the criteria for matching assured that all the controls were resident in the Grampian region at their date of exit from the study. Thus, of the 425 controls originally chosen to match the patients and shown in table I, only 36 were excluded because their place of residence at the time of exit could not be ascertained. Screening histories of immigrants to the Grampian region would have been incomplete in relation to both the existence of previous tests (in the patients in group 2) and the number of previous tests. This deficiency would not, however, have biased estimates of relative protection unless there was a difference in the proportion of immigrants among patients and controls; we have no information on this point, but there is no reason to suppose this to have been so. In particular, immigration would not have affected the estimates of relative protection by time since last negative smear; by definition, women who contributed to these estimates were resident in the region at the time the previous smear was registered.

The results presented here show a protective effect for the Pap test, a protection which is high immediately after a negative smear and declines as time elapses. The absence of any patients with a negative smear within the previous 12 months and the small number with a negative smear $12-23$ months previously suggest a high sensitivity of screening, as does the lack of any significant protective effect of two or more previous negative smears compared with one. The degree of protection is therefore high in the first three years after a negative smear but falls steadily thereafter, so that those screened six to 10 years previously have no greater protection than those who have delayed more than 10 years since a smear.

The estimate of a remaining threefold relative protection of a negative smear 10 or more years previously compared with no previous negative smear may be exaggerated owing to some of the smears by which the patients who had had no previous smear were detected being taken non-routinely. Nevertheless, some of the effect is likely to have been real, indicating that the tail of the distribution of asymptomatic disease duration extends beyond 10 years. This in turn implies that the relative protection at shorter time intervals, as given in table I, will be underestimates of the true effects. 
Several recent studies of the efficacy of screening for cervical cancer have used a case-control approach, three drawing controls from the general population and hence including both patients and controls who had never been screened, compared with our study in which all patients and controls had been screened at least once. In Toronto Clarke and Anderson found a relative protection against invasive cervical cancer of 2.7 in women who had been screened in the previous five years compared with those who had not; the effect was not appreciably changed when several possible confounding variables such as socioeconomic state, marital state, age at marriage, and age at first sexual intercourse were considered. ${ }^{15}$ Raymond et al obtained a relative protection of 3.2 associated with one or more previous negative smears in their study in Geneva, in which cases and controls were matched on nationality and marital state as well as age. ${ }^{16}$ The apparent diminution of this effect with increasing number of negative smears may be explained by repeated screening of patients with symptomatic tumours. For both these studies estimates of relative protection as a function of time since the last negative smear will soon be available (personal communication). In Cali, Colombia, Aristizabal et al estimated a relative risk of 9.4 for invasive cervical cancer among women not screened 12-72 months before the date of diagnosis of the case compared with those screened. ${ }^{17}$ This effect refers largely to a period 12-35 months before the date of diagnosis. Recently, a study in Milan, using hospital controls and relying on interview data to determine screening history, found a relative protection against invasive cervical cancer of 3.9 in women reporting at least one previous screen compared with those never screened, although positive or abnormal smears may have been included.18

Further studies will help to sharpen the estimates of relative protection as a function of time elapsed since a negative screen and to determine the effect of age. Our results suggest that high protection is given certainly in the first three years, but that by the seventh year much of this protection has disappeared, although there is still some protective effect relative to no screening even after 10 years. While, however, the percentage of invasive cancers prevented will obviously increase with successively shorter intervals between rescreening, the number of screening tests required to prevent an invasive cancer will rise, and it is this trade off that must be considered when formulating any screening policy either for a community or for the individual.

\section{References}

1 Hakama M. Trends in the incidence of cervial cancer in the Nordic countries. In: Magnus $\mathrm{K}$, ed. Trends in cancer incidence, causes and practical implications. New York: Hemisphere, 1981 .

2 Parkin DM, Day NE. Evaluation and planning of screening programmes. In Parkin DM, Wagner G, Muir CS, eds. The role of the registry in cancer control. He

efficacy of screening. Am f Epidemiol 1982;115:6-8.

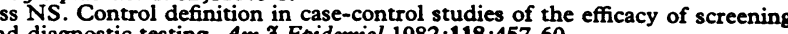
Apidemiol 1982;118:457-60.

ay NE, Walter SD. Simplified models of screening for chronic disease: estimation procedures from mass screening programmes. Biometrics 1984;40:1-14. 114:1013-33.

$7 \mathrm{Knox}$ EG. Ages and frequencies for cervical cancer screening. Br $\mathrm{f}$ Cancer 976;34:444-52

8 Walter SD, Day NE. Estimation of the duration of a preclinical disease state

Macgregor JE, Baird D. Detection of cervical carcinoma in the general population.

10 Macgregor JE, Teper $\mathrm{S}$. Mortality from carcinoma of cervix uteri in Britain.

1 Boyes DA. Morrison

cervical cancer screeningox EG, Draper GJ, Miller AB. A cohort study of 12 Storer BE, Wacholder S, Bn British Columbia. Clin Invest Med 1982;5:1-29. relative risk models to stratified Nat. Maximum likelihood fitting of genera

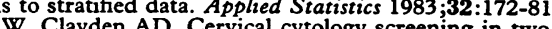
arkin DM, Collins W, Clayden AD. Cervical cytology screening in two Yorkshire areas: patterns of service. Public Health 1981 ;95:311-21.

14 Breslow NE, Day NE. Statistical methods in cancer research. Vol I. The analysis of case-control studies. Lyon: International Agency for Research on Cancer, (a)

"Pap" smear help prevent cervical cancer? Lancet 1979 ;ii: 1 -4.

(o estimate the detection of cancer of the cervix uteri by cytology. Revue d'Epidemiologie et de Sante Publique 1984;32:10-5.

17 Aristizabal N, Cuello C, Correa P, Collazos T, Haenszel W. The impact of vaginal cytology on cervical cancer risks in $\mathrm{Cali}$, Columbia. Int $\mathcal{F}$ Cancer $1984 ; 34: 5-9$.

18 La Vecchia C, Franceschi S, Decarli A, Fasoli M, Gentile A, Torgnoni G. "Pap" smear and the risk of cervical neoplasia: quantitative estimates from a case-control study. Lancet 1984 ;ii:779-82.

(Accepted 18 February 1985)

\title{
Predictive value of rectal bleeding in screening for rectal and sigmoid polyps
}

\author{
P H CHAPUIS, K J GOULSTON, O F DENT, A D TAIT
}

\begin{abstract}
Overt rectal bleeding is a common symptom of colorectal cancer and polyps but also occurs in apparently healthy people. It is not known how often this represents bleeding from an undiagnosed rectal or sigmoid polyp or cancer. Three hundred and nineteen apparently healthy men aged over 50, selected by random sampling, were interviewed and underwent flexible sigmoidoscopy to at
\end{abstract}

Gastroenterology Unit, Concord Hospital, Sydney 2139, Australia $P$ H CHAPUIS, DS, FRACS, senior lecturer in surgery

K J GOULSTON, MD, FRACP, director

A D TAIT, MB, FRACP, registrar

Australian National University, Canberra 2601, Australia

O F DENT, MA, PHD, senior lecturer in sociology

Correspondence and requests for reprints: Dr K J Goulston. least $30 \mathrm{~cm}$. Polyps of $10 \mathrm{~mm}$ or more in diameter were diagnosed in 12, one of whom also had an adenocarcinoma. Rectal bleeding during the previous six months was reported by 48 , four of whom were found to have polyps; seven polyps and one cancer were diagnosed among the 271 who reported no rectal bleeding. Rectal bleeding had a specificity of $86 \%$, a sensitivity of $33 \%$, and a positive predictive value of $8 \%$ for rectal or sigmoid polyps or cancer. Restricting the analysis to those subjects who regularly inspected their stools did not improve the predictive value.

Sigmoidoscopy in apparently healthy subjects with rectal bleeding will not result in the diagnosis of appreciable numbers of rectal and sigmoid polyps or cancers.

\section{Introduction}

Bleeding from the rectum is recognised as a common symptom of colorectal cancer and particularly of rectal cancer, in which it 